\title{
Does Immunohistochemically CD5 Positivity Matter In Diffuse Large B-Cell Lymphoma Patients? Turkish Multicenter Study
}

Ufuk Demirci ( $\square$ ufukdemirci3232@gmail.com )

Trakya University Medical Faculty

Hakkı Onur Kırkızlar

Trakya University Medical Faculty

Elif Gülsüm Ümit

Trakya University Medical Faculty

Vildan Gürsoy

Uludağ University

İbrahim Ethem Pınar

Uludağ University

Fahir Özkalemkaş

Uludağ University

Zeynep Tuğba Güven

Erciyes University

Leylagür Kaynar

Erciyes University

Fatma Keklik Karadağ

Ege University

Güray Saydam

Ege University

Ömer Ekinci

Fırat University

Mustafa Merter

Firat University

Merih Reis Aras

Health Sciences University

Mustafa Albayrak

Health Sciences University

Sedanur Karaman Gülsaran

Trakya University Medical Faculty

Volkan Baş 
Trakya University Medical Faculty

Berrin Balık Aydın

Medipol University, Medical Faculty

Hüseyin Saffet Beköz

Medipol University, Medical Faculty

\section{Ferda Can}

Ankara City Hospital

İmdat Dilek

Ankara City Hospital

Özgür Mehtap

Kocaeli University, Medical Faculty

\section{Erman Öztürk}

Medeniyet University, Medical Faculty

\section{Bengü Çöbanoğlu Şimşek}

Medeniyet University, Medical Faculty

\section{Murat Yıldırım}

Health Sciences University Gülhane Training and Research Hospital

\section{Meltem Aylı}

Health Sciences University Gülhane Training and Research Hospital

Ünal Ataş

Akdeniz University

\section{Ozan Salim}

Akdeniz University

\section{Mesut Ayer}

Çam Sakura Training and Research Hospital

\section{Elif Birtaş Ateşoğlu}

Koç University

\section{Olga Meltem Akay}

Koç University

\section{Meltem Kurt Yüksel}

Ankara University

\section{Semra Paydaş}

Cukurova University

\section{Selçuk Korkmaz}

Trakya University, Medical Faculty

\section{Fulya Öz Puyan}

Trakya University, Medical Faculty

Ahmet Muzaffer Demir

Trakya University, Medical Faculty 


\section{Research Article}

Keywords: Diffuse large B-cell lymphoma, CD 5, Double/Triple Expressor, CNS prophylaxis, c-MYC

Posted Date: October 27th, 2021

DOI: https://doi.org/10.21203/rs.3.rs-987276/v1

License: (c) (i) This work is licensed under a Creative Commons Attribution 4.0 International License. Read Full License 


\section{Abstract}

Background: Diffuse large B-cell lymphoma (DLBCL) is the most common sub-type of Non-Hodgkin lymphomas (NHL) and it is a very heterogeneous group of diseases. CD5 positivity is profound in a substantial patient population in DLBCL. In this population, female patient distribution is higher, LDH elevation, extra nodal involvement, bone marrow involvement, ECOG (Eastern Cooperative Oncology Group) performance score elevation and high international prognostic score (IPI> 2) are more frequent for CD5 - DLBCL. Also, it was observed that prognosis of CD5 + DLBCL was worse than CD5 - DLBCL. We aimed to determine the frequency of CD5 positivity in DLBCL in Turkey with this multicenter study.

Methods: The study, in order to get the overall parts from Turkey, including from each geographical area, 16 center and 9 cities were included. Each center retrospectively scanned the diagnostic pathology reports of DLBCL patients between January 2015-2021.

Results: Two thousand four hundred sixty-nine DLBCL patients were screened retrospectively. CD5 positivity was detected in 169 patients (6.84\%). The average age was 59 and $55.7 \%$ of the patients were male. Overall survival was 29.8 months. When evaluated with historical data in this group of patients, poor prognostic factors were found to be more common than CD5 - DLBCL patients.

Conclusion: Due to its prognostic effect, immunohistochemically, the presence of CD 5 in pathological samples of all DLBCL patients should be checked. The effect on prognosis in this patient group should not be forgotten while treatment and follow-up.

\section{Study Highlights}

- Considering its effect on patient survival and its frequency, it should not be underestimated;

- Due to its prognostic effect, CD5 must be applied immunohistochemically in pathological samples of all DLBCL patients

- GCB / non-GCB status should be checked in all DLBCL patients in the presence of Hans algorithm. Double / triple expressor distinction must be made.

- In all patients, FISH should be evaluated in terms of DHL / THL. Both the application of the Hans algorithm to each patient and the inability to evaluate DHL / THL for each patient with FISH were two aspects we had to develop.

- The awareness of the importance of CD5 presence among Hematology and Pathology physicians be increased.

- Although several studies are discussing the role of CNS prophylaxis in DLBCL, patients with CD5 + status may be defined as a CNS relapse risk. In our study number of patients received CNS prophylaxis were few but none of the patients with CNS relapse had previously received prophylaxis.

- Considering the data in the literature and the data in our study, the different evaluation of CD5 + patients, as in DHL / THL patients, seems to be an indisputable fact. The low survival rates with 
current primary care support this.

- With the survival and literature information, we think there is an unmet need for this subgroup of patients with low survival expectancy. Thus, we need new studies with novel treatment modalities to be combined or to replace the standard of care therapies.

\section{Introduction}

Diffuse large B-cell lymphoma (DLBCL) is the most common sub-type of Non-Hodgkin lymphomas (NHL), which constitutes $40 \%$ of patients. This group of diseases can be defined as an "umbrella entity" due to their heterogeneous nature. The fact that a $60 \%$ cure ${ }^{1,2,3}$ can be achieved after administration of first-line treatment makes it more important to elucidate this heterogeneity and identify high-risk patients with low response rates. The increase in the number of subgroups demonstrating this heterogeneity in the 2016 WHO Lymphoma classification ${ }^{4}$ has gained relevance and importance in clinical approaches. Double / Triple Hit (DHL/THL) $)^{5,6}$ is the most contemporary among these groups and highlights the importance of implementing risk-stratified treatment, which is the current treatment approach.

Another clinically remarkable group is immunohistochemically CD5 positivity in DLBCL, which is profound in a substantial part of the patient population. De novo DLBCL can be found CD5 positivity between $5 \%$ and $22 \%{ }^{7}$. As a pan T-cell marker, there are many properties that make CD 5 positivity important. In this population, unlike the general population of DLBCL patients, female patient distribution is higher, LDH elevation, extra nodal involvement, bone marrow involvement, ECOG (Eastern Cooperative Oncology Group) performance score elevation and high international prognostic score (IPI> 2) are more frequent. A poorer prognosis was observed in patients with CD5 positivity (+) DLBCL, as well as a higher relapse rate, versus $C D 5$ negative (-) $D L B C L^{7,8}$. According to these clinical findings, there are studies investigating more intensified treatment options other than R-CHOP (Rituximab, cyclophosphamide, doxorubicin, vincristine, and prednisone), which is the standard treatment option in DLBCL.

Because CD5 is a T lymphocyte marker and thus not essential in the diagnosis of DLBCL, it is not always examined immunohistochemically by pathologists. Therefore, different ratios in different studies can be seen. In addition, when we reviewed the literature, studies demonstrating its prevalence seem to be predominantly from Asian countries. Our aim was to determine the frequency of CD 5 positivity in DLBCL, and increase the awareness in Turkey, with this multicenter study. Our second aim was to investigate the presence and effect of other factors that may affect overall survival in these patients.

\section{Material / Methods}

The study was conducted together with the Turkish Society of Hematology, Lymphoma Scientific Subcommittee. This study included 16 centers and 9 cities that represent multiple geographic areas from all over Turkey. Each center retrospectively scanned the diagnostic pathology reports of DLBCL patients dating between January 2015-2021. Treatment and management data of patients with immunohistochemically CD5 positive DLBCL were evaluated by the centers. Pathology results without 
CD5 immunohistochemical staining were accepted as CD5 negative. In addition, the centers stated the total number of DLBCL patients diagnosed during this period. The total rate was calculated for comparison with historical data.

Primary central nervous system (CNS) lymphoma patients were excluded due to poor prognosis and different treatment regimens than R-CHOP. In the centers participating in the study, between January 2015 and 2021, the total number of newly diagnosed DLBCL patients examined were 2469 . CD 5 positivity was detected immunohistochemically in 169 patients. Data of 131 patients were available. Patients' age, gender, date of diagnosis, stage at diagnosis (Ann-Arbor). ECOG performance scales, LDH levels, R-IPI and NCCN-IPI scores, extra nodal involvement, bone marrow involvement, treatments modalities, posttreatment responses and follow-ups were retrospectively revealed from the patient files.

The study was conducted in accordance with the Declaration of Helsinki, Ethical Principles for Medical Research. This study was approved by Trakya University Faculty of Medicine Ethical Committee (TUTFBAEK2020/439).

\section{Pathological Findings}

Pathological findings were retrieved from pathology reports of the participating centers. All of the centers performed immunohistochemical studies on formalin-fixed, paraffin-embedded tissue sections. A panel of selected antibodies was used by the pathologists: CD20, CD3, CD5, CD10, BCL-2, BCL-6, MUM1, FOXP1, Ki-67, and MYC proto-oncogene protein (MYC). A cutoff level for dim to strong expression of CD5 was $\geq 50 \%$ of tumor cells for considering as immunopositivity. The cutoffs for positivity were $\geq 30 \%$ for CD10, BCL-6, and MUM-1 to classify these tumors as germinal center (GCB) or non-germinal center (non-GCB) cell-like immunophenotype according to Hans algorithm ${ }^{9}$. The positive cutoff for FOXP1 was $\geq 60 \%$ as proposed by Visco-Young algorithm ${ }^{10}$. The cutoffs for positive MYC or BCL-2 results were $\geq 40 \%$ and $\geq 50 \%$ of cells, respectively ${ }^{11}$ (Figure- 1 ).

Fluorescence in situ hybridization (FISH) was performed on cases using LSI dual-color break-apart probes for MYC and BCL6, and dual-color, dual-fusion probe for BCL2/IGH. Positive cases for rearrangements had positive signal in $\geq 15 \%$ of nuclei examined. Cases were designated as double-hit lymphoma if concurrent MYC and BCL2 or BCL6 were rearranged.

\section{Statistics}

Normality assumption was checked using Shapiro-Wilk test. Student T test and one-way analysis of variance were used to compare independent groups. Tukey Post-Hoc test was used to perform multiple comparisons. The log-rank test using the Kaplan-Meier method was performed for univariate survival analysis. The Cox Proportional-Hazards model with a forward selection method was used to identify the prognostic significance of risk factors on survival. Descriptive statistics were expressed as mean and 
standard deviation for numerical variables and frequency and percentage for categorical variables. A p value less than 0.05 considered as statistically significant. All statistical analyses were performed using SPSS version 20 (SPSS software, IBM Corporation, Armonk, NY).

\section{Results}

Two thousand four hundred sixty-nine $(2,469)$ DLBCL patients were screened retrospectively. CD5 positivity was detected immunohistochemically in 169 patients $(6.84 \%)$. Data of 131 patients were available. The average age was 59 (18 vs 88 ). $55 \%$ of the patients were 60 years and older. $55.7 \%$ of the patients were male. Overall survival was 29.8 months (0.1 vs 72.3 months). Progression-free survival (PFS) was 26.08 months. During their follow-up, 41 of 131 (31.3\%) patients died.

Pathology reports of 125 patients could be evaluated in terms of GCB / non-GCB (According to Hans algorithm) ${ }^{9}$. Seventy-six patients were non-GCB (61.7\%), 43 patients were GCB $(34.9 \%)$ and 4 patients were unclassified between GCB/non-GCB. The average Ki67 was $78.15 \%$. The ECOG score was found to be $\geq 2$ in $31.25 \%$ of the patients at the time of diagnosis. $57 \%$ patients had B symptoms. LDH was high in $65.4 \%$ of the patients. In 84 patients (66.7\%), Ann-Arbor was stage 3-4. It was seen that 114 patients were evaluated on the basis of bone marrow involvement. Bone marrow involvement was present in $23 \%$ of the patients. $70 \%$ patients had 1 or more extra nodal involvement. It was observed that 33 patients (42.8\%) had double / triple expressor. R-IPI score was high in $48 \%$ of patients, and NCCN-IPI was intermediate-high or high in $44.1 \%$ of the patients (Table- 1 ). It was observed that CNS prophylaxis was not applied frequently in these patients in the centers and there was no standard prophylaxis regimen between centers. It was determined that CNS prophylaxis was applied only to 19 patients. In patients who underwent remission after first-line therapy, 19 patients had relapse, of which 4 were from the CNS. It was observed that none of the patients received CNS prophylaxis during first line treatment.

\section{Evaluation of prognostic factors}

Age was found to be a significant variable. Overall survival was found to be significantly shorter in patients older than 60 years old. The mean survival is, statistically, significantly longer in patients under 60 years of age $(63,41$ vs 42,81 months, $p<0.01)$. There was no difference in survival between genders $(p=0,891)$. Patients with B symptom at the time of diagnosis $(57 \%)$ had a shorter mean survival $(p=0,002)$ (Figure-2).

Bone marrow involvement were screened with biopsy in 114 of the patients and revealed that $23 \%$ had bone marrow involvement. The mean survival of patients with bone marrow involvement was statistically significantly lower $(32.03-58.27$ months, $p<0.01) .113$ patients had radiological imaging for staging at the time of diagnosis and $70 \%$ of the patients had extra nodal involvement. Mean survival was statistically significantly lower in patients with extra nodal involvement $(66,23$ vs 46,90 months, $p=0.02)$ (Figure-3). 
We were able to evaluate LDH values in 130 patients. $65.3 \%$ of the patients had higher than normal LDH values. Similar to NCCN-IPI scoring, we divided the patients into 3 groups: as normal, up to 3 times as high, and $>3$ times as high. We found that high LDH was statistically significant in survival $(p<0.01)$. $27.5 \%$ of the patients had a higher than grade $1 \mathrm{ECOG}$ score and survival was shorter in these patients. ( $p$ $<0.01$ ). R-IPI score was found to be high $(>3)$ in $47 \%$ of the patients. Patients with higher R-IPI scores had a shorter survival rate $(p<0.01)$. Similarly, survival was short in patients with both high-intermediate and high risk NCCN-IPI scores $(p<0.01)$ (Figure- 3-4).

We were able to evaluate 131 patients for double / triple expressor status and found that 54 of the patients did not possess Bcl-2, Bcl6 and/or C-myc markers. In this respect, 33 (42.8\%) of 77 patients who were fully evaluated immunohistochemically had a double / triple expressor. If we accept 54 patients whose evaluation is not complete immunohistochemically as no double / triple expressor, we can discuss the presence of double / triple expressor in $24.8 \%$ of the patients. Overall survival (OS) was shorter in these patients $(p=0.095)$ (Figure- 4$)$. It was observed that only 10 patients were evaluated in terms of DH/THL with FISH (fluorescent in situ hybridization). Two of these patients were double / triple hit. Additionally, patients were evaluated immunohistochemically according to the Hans algorithm, patients with non-GCB morphology had a shorter mean survival $(p=0.348)$ (Figure- $2-3)$.

It was observed that the first line treatment of 11 patients was a more intensive treatment (DA-EPOCH-R, $\mathrm{R}$-CHOEP, Hyper-CVAD). The mean survival of these patients compared to patients who received R-CHOP as first-line therapy was similar $(\mathrm{p}=0.997)$ (Table- 2$)$.

In terms of overall survival, when multivariate analysis was performed by excluding R-IPI and NCCN-IPI, which are among the other data, it was seen that $\geq 60$ years of age, ECOG $\geq 2$ and $\geq 1$ extra nodal involvement had an effect on survival. The same findings ( $\geq 60$ years of age, ECOG $\geq 2$ and $\geq 1$ extra nodal involvement) were also valid for PFS in multivariate analysis (Figure- 5-6-7).

\section{Discussion}

Interpreted as a pan T-cell marker, CD5 is a monomeric type 1 transmembrane glycoprotein. This protein, which has both an intracellular and extracellular domain, weighs $67 \mathrm{kDa}$. CD5 gene maps to the chromosome 11q12.2 region. Although it is frequently expressed from T cells, it is also expressed at a low level by a small subset of naive $B$ lymphocytes ${ }^{12}$. CD5 inhibits signaling downstream of the $B$ cell receptor (BCR) and modifies intracellular calcium mobilization. It also suppresses the release of IL-2, resulting in increased production of BCR-mediated IL-10, which is an anti-inflammatory marker and a survival factor for B-cells. In addition, there are studies showing that it is associated with the activation of the ERK1 / 2, PI3K, STAT3 and NFAT2 signal pathways in the presence of CD5 positive B cells and is thus related with poor prognosis ${ }^{7,12}$. Also, CD 5 positive $B$ cells can produce autoantibodies, which is also related with autoimmune events in chronic lymphocytic leukemia $(C L L)$ and mantle cell leukemia $(\mathrm{MCL})^{13}$. High LDH, bone marrow involvement, presence of extra nodal involvement, high IPI score, high ECOG performance score and CNS recurrence, which are known as predictive factors and are more 
common in the group with CD5 + DLBCL patients. The survival of these patients is also observed to be shorter compared to the CD5 - group ${ }^{8}$.

The frequency of CD5 positivity, which is more observed in the differential diagnosis of CLL and MCL, is variable in de novo DLBCL patients. In a retrospective study by Na H.Y, et al. about the characteristics of CD5 + DLBCL patients in Korea, CD5 positivity was found to be $7.4 \%{ }^{14}$. In a multi-center study by Yamaguchi et al in Japan, this frequency was found $10 \%{ }^{15}$. However, in large-scale studies in Japan, prevalence rates of CD 5 positivity may vary widely, from 5 to $22 \%{ }^{7,15}$. Besides these, in a multi-center large-scale study with data from Western countries, CD5 positivity ratio in DLBCL is (5.5\%) lower than in East Asian countries ${ }^{16}$. When we look at the rate of CD5 + DLBCL lymphoma among DLBCL patients, in our study we found that it is $6.84 \%$ and this rate is closer to the rate found in Western countries unlike East Asian countries. One of the most important reasons for these differences is that CD5 staining in immunohistochemically, which as a pan-T marker, is not performed in every DLBCL patient in our country. If this evaluation can be performed in all newly diagnosed DLBCL patients in Turkey, we think that these rates may be higher, similar to what is seen in the studies coming from East Asia. When we compare the age distribution with other studies, the number of patients older than 60 and over was more common ( $\geq$ 60 age: $55 \%$ ) or similar. Survival was shorter in this group, as expected. Although, there is a predominance of female patient distribution in CD5 + DLBCL patients in studies from East Asian countries. But in our study, male patients were higher (55.7\%) and similar to the data from Western countries.

In DLBCL patients, the chance of obtaining remission with treatment is $50-60 \%$ according to the current standard of care. In addition, we know that there are many factors that affect survival. When the patients are evaluated in the presence of clinical scores, the 5-year survival rate in patients with low IPI score is $90 \%$, while this rate decreases to $60 \%$ with high IPI score. Also, when evaluated according to the cell of origin, according to Hans algorithm, 5-year OS was 48-56\% in non-GCB subtype, while this rate was 73$78 \%$ in GCB subtype. The 5-year survival rate in the DHT / THT subtype, which is defined as an aggressive subtype and is found in $6 \%-14 \%$ of DLBCL patients, appears to be very low and nearly $18 \%^{1,17}$. As another variable, when screening the literature regarding the effect of CD 5 presence on prognosis, we see that the data are similar in the other studies and the presence of CD5 positivity reduces survival. The 5-year overall survival (OS) is $35.5 \%$ in CD $5+$ DLBCL patients, and it has been found to be shorter than general DLBCL patient population ${ }^{12}$. In our study, immunohistochemically, we found that the mean survival was 29.8 months in CD5 + DLBCL patients. During this 5-year follow-up, we found that $31.3 \%$ of the patients had died. The study had two important limiting factors. First, we do not have the survival statistics of CD5 - control group. So we had to evaluate only CD5 + DLBCL patients in our study, and then we could make the comparison historically with the CD $5+$ and - DLBCL groups in the literature. The second important factor is the study was retrospective.

In addition to the shorter OS of CD5 + DLBCL patients, these patients have higher LDH, IPI elevation, advanced Ann-Arbor frequency, poor performance score (ECOG> 1), and bone marrow involvement at the 
time of diagnosis compared to CD5 - DLBCL patients. CNS relapse is more common in patients with CD5 positivity. CD5 + DLBCL is more often in the non-GCM / ABC phenotype. Also, the presence of double / triple expressor or double / triple hits (14.4\%) is more common in these patients at the time of diagnosis ${ }^{12,14,15,16,18}$.

The age and gender distribution at the time of diagnosis is variable. In studies from East Asian countries, the frequency of female patients is significantly higher ${ }^{12,14,15}$. However, there is no difference in gender distribution in Western countries ${ }^{16}$. In our data, it was seen that male patients were in the majority (55.7\%). Again, in most of the studies, we can say that the group > 60 years was more common in CD5 + patients. Xu-Monette et al. in the study conducted on CD5 + DLBCL patient data from western countries, it is seen that $76.7 \%$ of $C D 5+$ patients are over 60 years old ${ }^{16}$. But, in a single-center study by Tang $\mathrm{H}$. et al in China, $53.3 \%$ of CD5 + DLBCL patients were below the age of 60, in addition, the group over 60 years of age was more common in CD5 - patients ${ }^{12}$. In our data, the rate of patients, 60 years and older, are higher (55\%) (Table- 3).

Central nervous system relapse is more common in CD5 + DLBCL patients. Its mechanism is still not understood. In the study by Zhang et al, it was observed that CNS involvement in relapsed DLBCL patients was $35 \%$ in CD5 + patients, while it was $19 \%$ in CD5 - patients ${ }^{18}$. Similarly, in the study by Thakral B. et al., CNS relapsed was 33.3\% in CD5 + patients and 15.6\% in CD5 - patients ${ }^{19}$. In our data, it was seen that 19 patients relapsed and only 4 patients relapsed from the CNS region ( $3 \%$ of all patient, $21 \%$ of all relapses). When the rate of CNS relapse in examined our CD $5+$ patients, compared with ratio in the literature, it was seen that although it was higher than in CD 5 - patients, it was not as common as in CD5 + patients. Also, we found that not all of these patients received CNS prophylaxis in our study. In addition, we saw that the CNS prophylaxis number and protocol of the centers were not standard.

In our data, $64.6 \%$ of the patients had high LDH, and $13.4 \%$ had 3 -fold or more. Also, $23 \%$ of the patients had bone marrow involvement, $70 \%$ had extra nodal involvement, $57 \%$ of the patients had B symptoms. At $66.6 \%$, Ann-Arbor was seen as stage 3-4. And the presence of these factors had a significant relationship with survival. In addition to the higher frequency of all these factors that have impact on prognosis for CD5 + DLBCL patients. In a study with a small number of patients from Taiwan the presence of $\mathrm{CD} 5+$ was seen as the only adverse prognostic factor in multivariate analysis ${ }^{20}$.

As with $\mathrm{DHL} / \mathrm{THL}$, there are studies for intensive treatments for CD 5 + patients, which is a poor prognostic factor. Increased overall survival with the introduction of Rituximab seems to be valid also for CD $5+$ patients. In a study by Hyo R et al. showed that addition of Rituximab to chemotherapy, similarly increased OS and progression-free survival (PFS) in both CD5 + and CD5-groups ${ }^{21}$. Also, in a study by Miyazaki K. et al revealed that addition of Rituximab to chemotherapy in CD $5+$ DLBCL patients, it is seen that the addition of Rituximab to chemotherapy significantly increases $0 S^{22}$. In a retrospective study by Thankral B. et al., in which DLBCL patients treated with R-EPOCH chemotherapy, with a 28.5-month median follow-up, $37.5 \%$ of CD5 + patients had died, compared with $9.6 \%$ of patients with CD5 - ${ }^{19}$. In the 
study conducted by Zhang $F$. et al to evaluate the effect of intensive treatment on survival, the effectiveness of DA-EPOCH-R and R-CHOP treatments were compared. In the study, it was observed that PFS and OS were better in both CD $5+$ and CD5 - groups in patients who received DA-EPOCH-R in shortterm follow-up. In the long-term follow-up, this difference was not seen for OS in CD5 + patients. Also, in another study with a small group of patients with short-term follow-up, we can say that the DA-EPOCH-R combined with high-dose methotrexate regimen had a better survival in the $\mathrm{CD} 5+$ patient group ${ }^{23}$. In our study, it was observed that the first line treatment of 11 patients was a more intensive treatment (DAEPOCH-R, R-CHOEP, Hyper-CVAD). The mean survival of these patients compared to patients who received $\mathrm{R}-\mathrm{CHOP}$ as first-line therapy was similar. The low number of patients receiving intensive treatment seems to be an important limiting factor in this comparison.

\section{Declarations}

Funding: There is no additional financial resource for this study.

Conflict of interest: No conflict of interest for all authors.

Ethics approval: TUTF-BAEK2020/439

Informed consent: Informed consent was obtained from all subjects as a retrospective study. Also, imformed consent was obtained from a parent and/or legal guardian for patients who died.

Precis for use in the Table of Contents: CD5 + DLBCL has poor prognosis and should be investigated in all DLBCL patients

\section{References}

1. Liu, Y. \& Barta, S. K. Diffuse large B-cell lymphoma: 2019 update on diagnosis, risk stratification, and treatment. Am J Hematol, 94, 604-616 (2019).

2. Tilly, H., Silva, M. G. \& Vitolo, U. and et al. Diffuse large B-cell lymphoma (DLBCL): ESMO Clinical Practice Guidelines for diagnosis, treatment and follow-up. Annals of Oncology, 26 (Supplement 5), v116-v125 (2015).

3. Li, S., Young, K. H. \& Medeiros, J. Diffuse large B-cell lymphoma.Pathology. 2018Jan;50(1):74-87.

4. Jaffe, E. S. et al. WHO Classification of Tumours of Haematopoietic and Lymphoid Tissues. Introduction and overwiev of the classification of lymphoid neoplasm.190-198(2017)

5. Huang, S., Nong, L. \& Wang, W. and et al. Prognostic impact of diffuse large B-cell lymphoma with extra copies of MYC, BCL2 and/or BCL6: comparison with double/triple hit lymphoma and double expressor lymphoma. Diagn. Pathol, 14, 81 (2019).

6. Sukswai, N., Lyapichev, K., Khoury, J. D. \& Medeiros, L. J. Diffuse large B-cell lymphoma variants: an update. Pathology, Jan;52 (1), 53-67 (2020). 
7. Xu, Y., Sun, W., Li, F. \& De Novo, C. D. Diffuse Large B-Cell Lymphoma: Biology, Mechanism, and Treatment Advances. Clinical Lymphoma, Myeloma \& Leukemia, e782-90(2020)

8. Ting, C. Y. et al. Clinical Significance of BCL2, C-MYC, and BCL6 Genetic Abnormalities, Epstein-Barr Virus Infection, CD5 Protein Expression, Germinal Center B Cell/Non-Germinal Center B-Cell Subtypes, Co-expression of MYC/BCL2 Proteins and Co-expression of MYC/BCL2/BCL6 Proteins in Diffuse Large B-Cell Lymphoma: A Clinical and Pathological Correlation Study of 120 Patients. Int J Med Sci. Apr 20;16(4):556-566(2019)

9. Hans, C. P. et al. Confirmation of the molecular classification of diffuse large B-cell lymphoma by immuno- histochemistry using a tissue microarray. Blood, 103, 275-282 (2004).

10. Visco, C. et al. Comprehensive gene expression profiling and immunohistochemical studies support application of immunophenotypic algorithm for molecular subtype classification in diffuse large Bcell lymphoma: a report from the International DLBCL Rituximab-CHOP Consortium Program Study. Leukemia. 2012;26: -2113. (2013)

11. Yoshioka, T. et al. Cytogenetic features of de novo CD5- positive diffuse large B-cell lymphoma: chromosome aberrations affecting 8p21 and 11q13 constitute major subgroups with different overall survival. Genes Chromosomes Cancer, 42, 149-157 (2005).

12. Tang, H., Zhou, H. \& Wei, J. and et al. Clinicopathologic significance and therapeutic implication of de novo CD5+ diffuse large B-cell lymphoma. Hematology. Dec, 24 (1), 446-454 (2019).

13. Jain, P., Fayad, L. E. \& Rosenwald, A. and et all. Recent advances in de novo CD5+ diffuse large B cell lyphoma. Am J Hematol. Sep, 88 (9), 798-802 (2013).

14. Na, H. Y. et al. Characteristics of CD5-positive diffuse large B-cell lymphoma among Koreans: High incidence of BCL2 and MYC double-expressors. PLoS One. Oct 23;14(10): e0224247(2019)

15. Yamaguchi, M. et al. De novo CD5+ diffuse large B-cell lymphoma: a clinicopathologic study of 109 patients. Blood. 1;99(3):815-21(2002)

16. Xu-Monette, Z. Y. et al. Clinical and biological significance of de novo CD5+ diffuse large B-cell lymphoma in Western countries. Oncotarget. Mar, 20 (8), 5615-5633 (2015).

17. Sehn, L. H. \& Salles, G. Diffuse Large B-Cell Lymphoma.N Engl J Med. 384;9 (2021)

18. Zhang, F., Li, L. \& Zhang, L. and et al. Prognostic analysis of CD5 expression in double-hit diffuse large B-cell lymphoma and effectiveness comparison in patients treated with dose-adjusted EPOCH plus rituximab/R-CHOP regimens. Blood Lymphat Cancer, 19, 933-943 (2019).

19. Thakral, B. et al. Prognostic impact of CD5 expression in diffuse large B-cell lymphoma in patients treated with rituximab-EPOCH. Eur J Haematol, 98 (4), 415-421 (2017).

20. Chuang, W. Y., Chang, H. \& Shih, L. Y. and et al. CD5 positivity is an independent adverse prognostic factor in elderly patients with diffuse large B cell lymphoma. Virchows Arch, 467 (5), 571-582 (2015).

21. Hyo, R., Tomita, N. \& Takeuchi, K. and et al. The therapeutic effect of rituximab on CD5-positive and CD5-negative diffuse large B-cell lymphoma. Hematol Oncol, 28 (1), 27-32 (2010). 
22. Miyazaki, K., Yamaguchi, M. \& Suzuki, R. and et al. CD5-positive diffuse large B-cell lymphoma: a retrospective study in 337 patients treated by chemotherapy with or without rituximab. Annals of Oncology, 22, 1601-1607 (2011).

23. Miyazaki, K., Asano, N. \& Yamada, T. and et al. DA-EPOCH-R combined with high-dose methotrexate in patients with newly diagnosed stage II-IV CD5-positive diffuse large B-cell lymphoma: a single-arm, open-label, phase II study. Haematologica Volume, 105 (9), 2308-2315 (2020).

\section{Tables}




\begin{tabular}{|c|c|}
\hline Number & 131 \\
\hline Age (Mean, Years) & $59(18-88)$ \\
\hline Age $<60 /(\%)$ & $59 / 72(45 \%$ / $55 \%)$ \\
\hline \multirow[t]{2}{*}{ Gender (M/F) } & $73 / 58$ \\
\hline & $55.7 \% / 44.3 \%$ \\
\hline \multirow[t]{2}{*}{ GCB / non-GCB / Nos (\%) } & $43 / 76 / 4$ \\
\hline & $34.9 \% / 61.7 \% / 3.4 \%$ \\
\hline Ki67 \% (Mean) & $78.15 \%$ \\
\hline \multirow[t]{2}{*}{$\mathrm{ECOG}^{3} 2 /<2$} & $40 / 88$ \\
\hline & $(31.25 \% / 68,75)$ \\
\hline \multirow[t]{2}{*}{ B Symptoms (Y/N) } & $73 / 55$ \\
\hline & $(57 \% / 43 \%)$ \\
\hline LDH (Normal / High / 33 fold) & Normal: 45 (35.4\%) \\
\hline \multirow[t]{2}{*}{ (127 patients had LDH data) } & High - <3 fold: 65 (51.2\%) \\
\hline & >3 fold: $17(13.4 \%)$ \\
\hline Bone Marrow Involvement (\%) & 26 patients $(23 \%)$ \\
\hline Extra nodal Involvement (\%) & 91 patients $(70 \%)$ \\
\hline \multirow{2}{*}{\multicolumn{2}{|c|}{$\begin{array}{l}\text { Ann-Arbor } \\
\text { (126 patients had Ann-Arbor data) }\end{array}$}} \\
\hline & \\
\hline Stage I & $20(15,9 \%)$ \\
\hline Stage II & $22(17,5 \%)$ \\
\hline Stage III & $26(20,6 \%)$ \\
\hline Stage IV & $58(46 \%)$ \\
\hline Double / Triple Expressor & 33 patients \\
\hline (77 patients had Bcl-2, Bcl6 and or C-myc data) & $(42.8 \%)$ \\
\hline \multirow[t]{2}{*}{$R-|P|<3,33$} & $66 / 61$ \\
\hline & $(52 \% / 48 \%)$ \\
\hline \multirow[t]{2}{*}{$N C C N-I P I^{3} 4$ and $<6$} & $34 / 127$ \\
\hline & (26.7\%) \\
\hline
\end{tabular}


Table-2: Comparison of prognostic markers in CD $5+$ patients group 


\begin{tabular}{|c|c|c|c|}
\hline Table -2 & Overall Survival (months) & 95\% Confidence Interval & $\mathbf{P}$ \\
\hline \multicolumn{4}{|l|}{ Age } \\
\hline$<60$ & 63,40 & $57.05-69.76$ & \multirow[t]{2}{*}{$<0.001$} \\
\hline 60 & 42.98 & $34.74-50.87$ & \\
\hline \multicolumn{4}{|l|}{ B symptoms } \\
\hline Yes & 44.34 & $36.55-52.12$ & \multirow[t]{2}{*}{0.002} \\
\hline No & 62.44 & $55.56-69.32$ & \\
\hline \multicolumn{4}{|l|}{ LDH } \\
\hline Normal & 61.58 & $53.85-69.31$ & \multirow{3}{*}{$<0.001$} \\
\hline Upper $-<3$ fold & 51.61 & $43.87-59.36$ & \\
\hline 3 fold & 25.94 & $9.49-42.39$ & \\
\hline \multicolumn{4}{|l|}{ ECOG } \\
\hline $0-1$ & 62.31 & $57.05-67.57$ & \multirow[t]{2}{*}{$<0.001$} \\
\hline 2 & 29.36 & $18.71-40.02$ & \\
\hline \multicolumn{4}{|l|}{ R-IPI } \\
\hline $1-2$ & 63.60 & $57.81-69.39$ & \multirow[t]{2}{*}{$<0.001$} \\
\hline 3 & 38.27 & $29.33-47.22$ & \\
\hline \multicolumn{4}{|l|}{ NCCN-IPI } \\
\hline$<4$ & 62.30 & $56.39-68.20$ & \multirow[t]{3}{*}{$<0.001$} \\
\hline 4 & 42.33 & $31.66-52.99$ & \\
\hline 6 & 24.24 & $11.01-37.48$ & \\
\hline \multicolumn{4}{|l|}{ GCB / non-GCB } \\
\hline GBC & 57.27 & $48.42-66.11$ & \multirow[t]{2}{*}{0.348} \\
\hline Non-GCB & 53.93 & $44.41-59.60$ & \\
\hline \multicolumn{4}{|c|}{ Double/Triple expressor } \\
\hline Yes & 43.82 & $32.28-55.37$ & \multirow[t]{2}{*}{0.095} \\
\hline No & 56.18 & $47.58-64.77$ & \\
\hline \multicolumn{4}{|c|}{ Bone marrow involvement } \\
\hline Yes & 32.03 & $19.12-44.94$ & $<0.001$ \\
\hline
\end{tabular}




\begin{tabular}{|lccc|}
\hline No & 58.27 & $52.30-64.23$ & \\
\hline \multicolumn{2}{|l|}{ Extra nodal involvement } & & 0.002 \\
Yes & 46.90 & $39.87-53.93$ & \\
No & 66.23 & $60.16-72.30$ & \\
Treatment & & & 0.997 \\
R-CHOP & 54.69 & $48.94-60.44$ & \\
Intensive Treatment & 40.39 & $28.34-52.44$ & \\
\hline
\end{tabular}

Table-3: Comparison with literature data of presence of prognostic markers in CD5 + and - patients group 


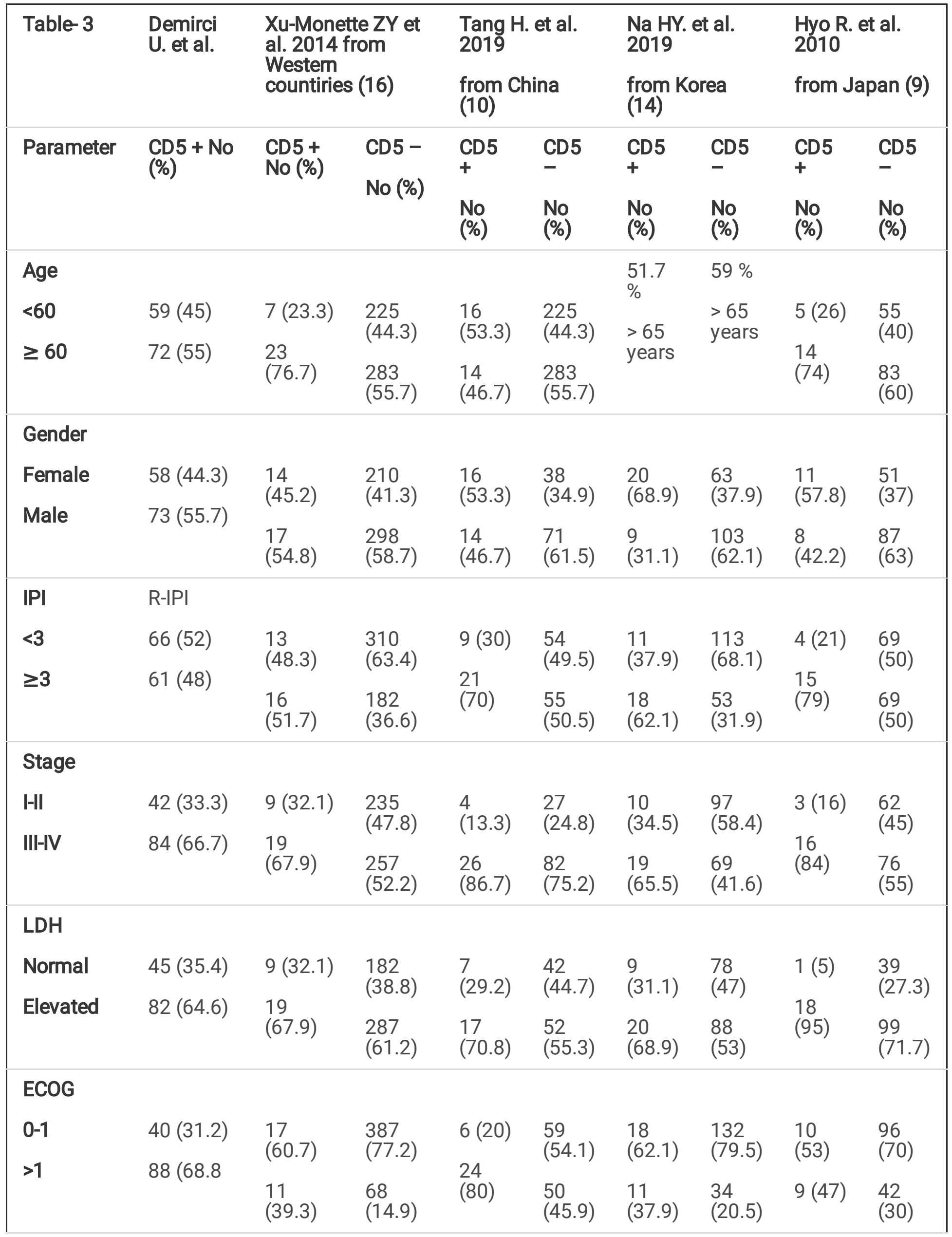




\begin{tabular}{|c|c|c|c|c|c|c|c|c|c|}
\hline \multirow[t]{2}{*}{$\begin{array}{l}\text { Extra } \\
\text { nodal inv. } \\
0-1 \\
>1\end{array}$} & \multirow[t]{2}{*}{$\begin{array}{l}91 \\
\text { patients } \\
\text { have } \\
\text { extra } \\
\text { nodal inv } \\
70 \%\end{array}$} & $\begin{array}{l}22 \\
(76.7)\end{array}$ & $\begin{array}{l}369 \\
(77.2)\end{array}$ & $\begin{array}{l}23 \\
(76.7)\end{array}$ & $\begin{array}{l}74 \\
(68.5)\end{array}$ & $\begin{array}{l}16 \\
(55.1)\end{array}$ & $\begin{array}{l}30 \\
(18.1)\end{array}$ & \multirow{2}{*}{$\begin{array}{l}9(47) \\
10 \\
(53)\end{array}$} & \multirow{2}{*}{$\begin{array}{l}92 \\
(67) \\
46 \\
(33)\end{array}$} \\
\hline & & $8(23.3)$ & $\begin{array}{l}117 \\
(22.8)\end{array}$ & $\begin{array}{l}7 \\
(23.3)\end{array}$ & $\begin{array}{l}34 \\
(31.5)\end{array}$ & $\begin{array}{l}13 \\
(44.9)\end{array}$ & $\begin{array}{l}136 \\
(81.9)\end{array}$ & & \\
\hline \multicolumn{10}{|l|}{$\begin{array}{l}\text { B } \\
\text { symptoms }\end{array}$} \\
\hline Absent & \multirow{2}{*}{$\begin{array}{l}55(43) \\
73(57)\end{array}$} & $(46.4)$ & (65.9) & $\begin{array}{l}15 \\
(50)\end{array}$ & (61.5) & $(72.4)$ & $\begin{array}{l}125 \\
(75.3)\end{array}$ & \multirow{2}{*}{$\begin{array}{l}6(32) \\
13 \\
(68)\end{array}$} & $\begin{array}{l}93 \\
(67)\end{array}$ \\
\hline Present & & $\begin{array}{l}15 \\
(53.6)\end{array}$ & $\begin{array}{l}165 \\
(34.1)\end{array}$ & $\begin{array}{l}15 \\
(50)\end{array}$ & $\begin{array}{l}42 \\
(38.5)\end{array}$ & $\begin{array}{l}8 \\
(27.6)\end{array}$ & $\begin{array}{l}41 \\
(24.7)\end{array}$ & & $\begin{array}{l}45 \\
\text { (33) }\end{array}$ \\
\hline \multicolumn{10}{|l|}{$\begin{array}{l}\text { Bone } \\
\text { marrow } \\
\text { inv. }\end{array}$} \\
\hline Absent & 87 (76) & $\begin{array}{l}15 \\
(57.7)\end{array}$ & $\begin{array}{l}399 \\
(91.1)\end{array}$ & $\begin{array}{l}12 \\
(54.5)\end{array}$ & $\begin{array}{l}70 \\
(80.5)\end{array}$ & $\begin{array}{l}18 \\
(62.1)\end{array}$ & $\begin{array}{l}146 \\
(87.9)\end{array}$ & \multirow[t]{2}{*}{ - } & \multirow[t]{2}{*}{ - } \\
\hline Thesein & $20(<0)$ & $\begin{array}{l}11 \\
(42.3)\end{array}$ & $\begin{array}{l}39 \\
(8.9)\end{array}$ & $\begin{array}{l}10 \\
(45.5)\end{array}$ & $\begin{array}{l}17 \\
(19.5)\end{array}$ & $\begin{array}{l}11 \\
(37.9)\end{array}$ & $\begin{array}{l}20 \\
(12.1)\end{array}$ & & \\
\hline \multirow{2}{*}{$\begin{array}{l}\text { GCB } \\
\text { non-GCB }\end{array}$} & 43 (34.9) & 7 (23.3) & $\begin{array}{l}268 \\
(53.2)\end{array}$ & $\begin{array}{l}2 \\
(7.4)\end{array}$ & $\begin{array}{l}25 \\
(31.3)\end{array}$ & \multirow[t]{2}{*}{ - } & \multirow[t]{2}{*}{-} & \multirow[t]{2}{*}{ - } & \multirow[t]{2}{*}{ - } \\
\hline & 76 (61.7) & $\begin{array}{l}23 \\
(76.7)\end{array}$ & $\begin{array}{l}236 \\
(46.8)\end{array}$ & $\begin{array}{l}25 \\
(92.5)\end{array}$ & $\begin{array}{l}55 \\
(68.7)\end{array}$ & & & & \\
\hline
\end{tabular}

\section{Figures}




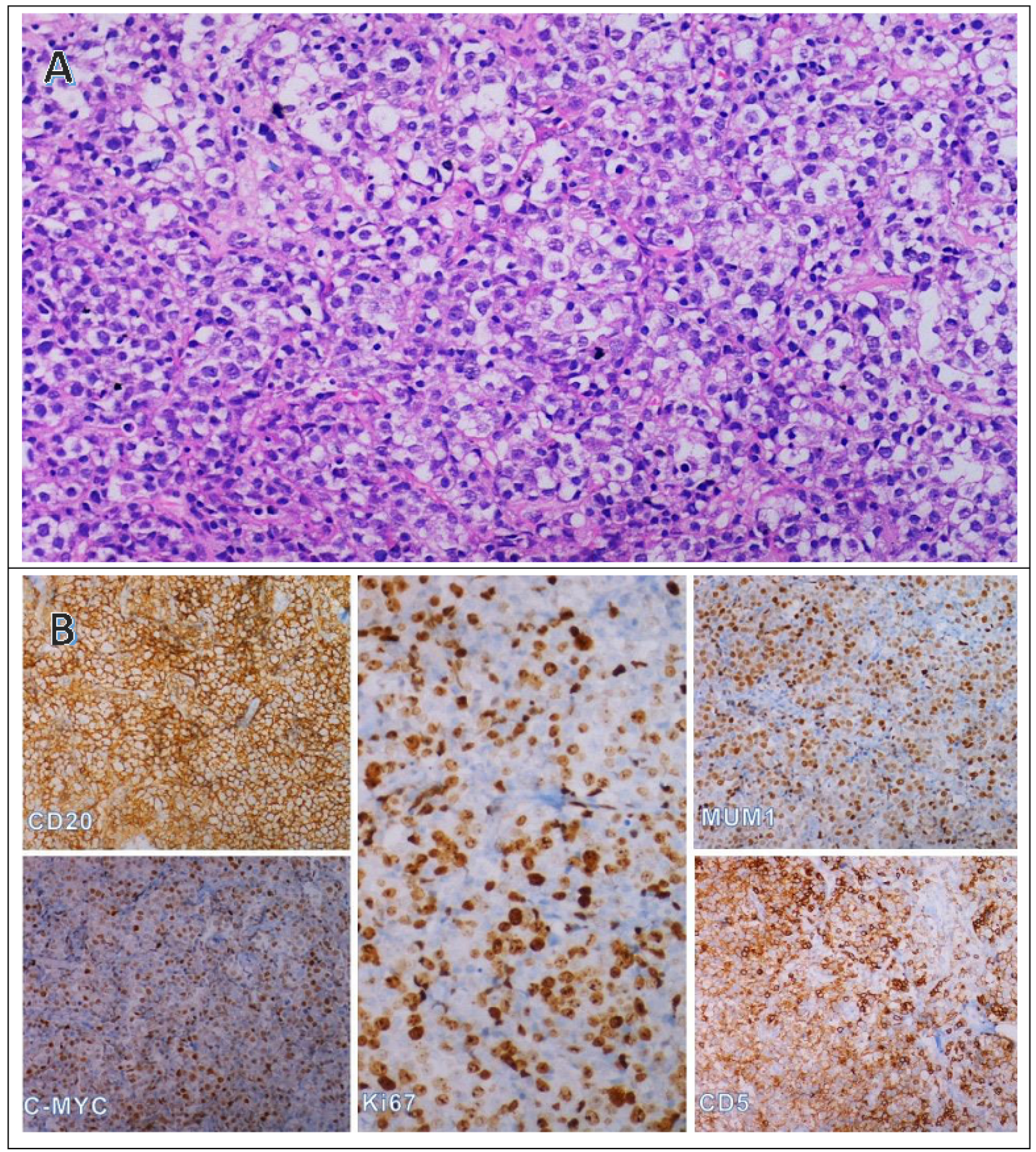

\section{Figure 1}

Many of the cases showed large pleomorfic cell groups with vacuolar cytoplasm and vesicular nucleus (A). Tumor cells were positive for CD20, MUM1, C-MYC and CD5. High Ki67 proliferative leve was observed on most of the cases (B). 

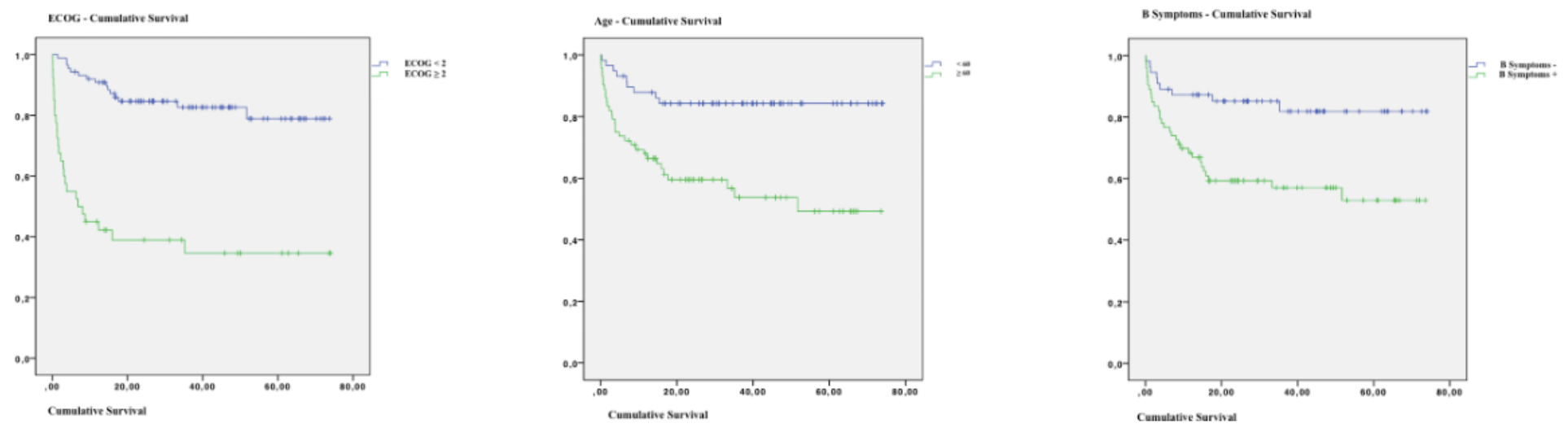

\section{Figure 2}

Evaluation of survival with Prognostic factors (ECOG, Age, B symptoms) in CD $5+$ patients
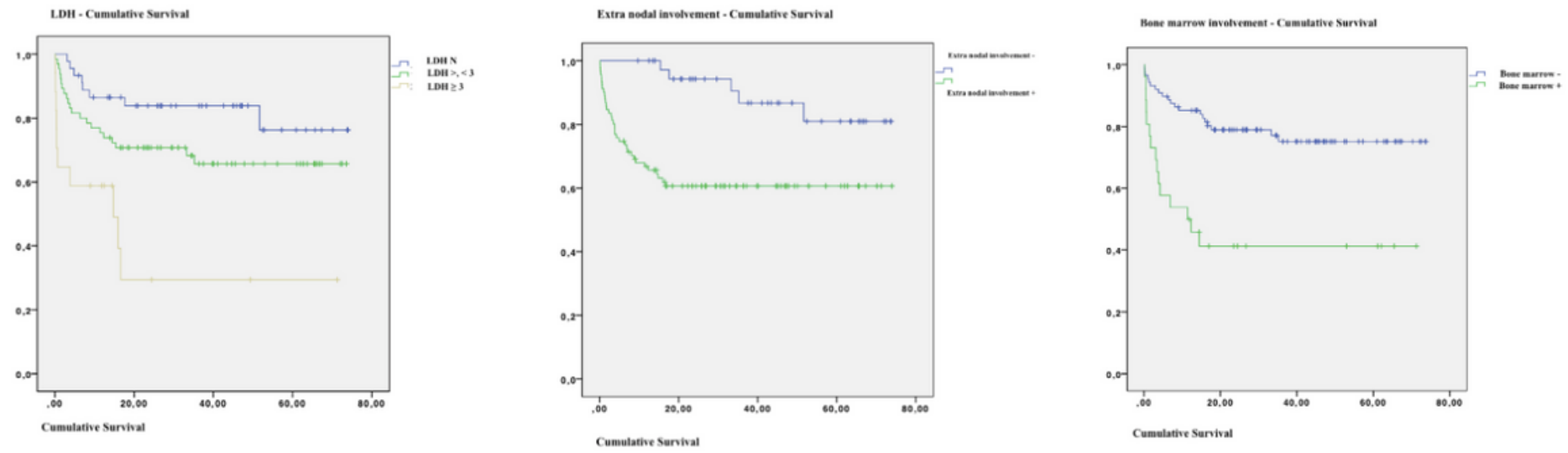

\section{Figure 3}

Evaluation of survival with Prognostic factors (LDH, EN, BM) in CD 5 + patients
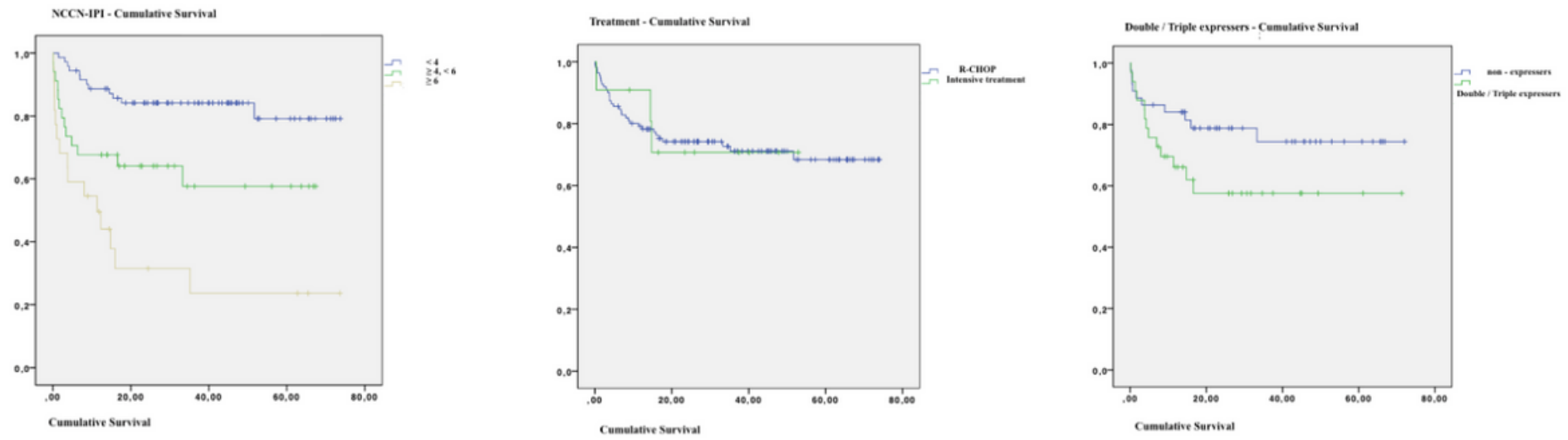

Figure 4 
Evaluation of survival with Prognostic factors (NCCN-IPI, Treatment, D/T expr) in CD5 + patients
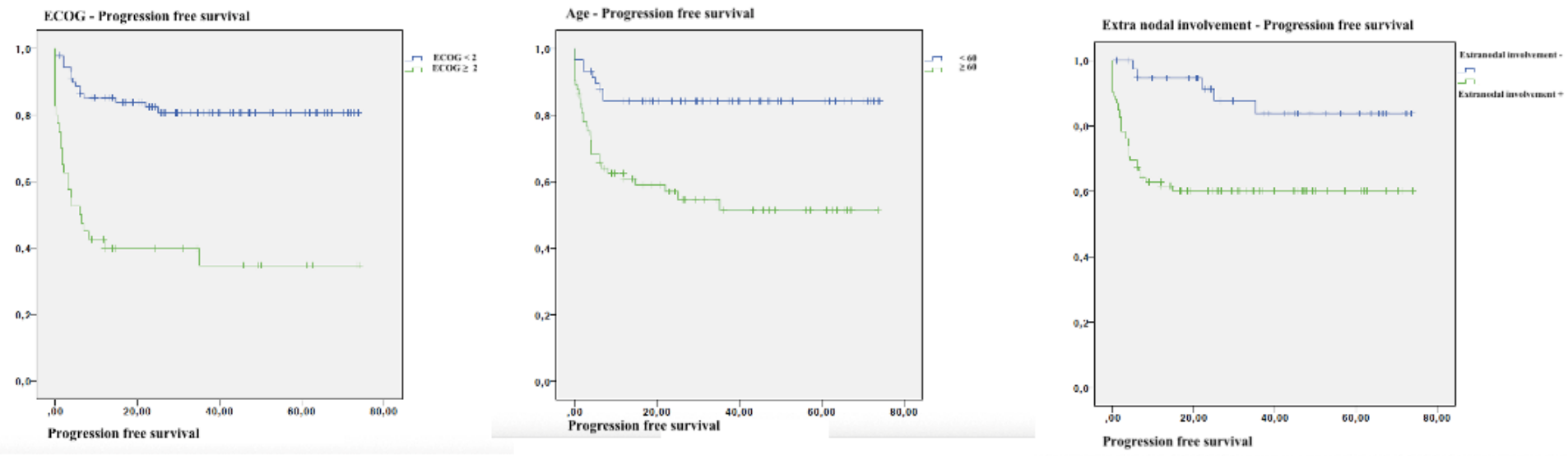

\section{Figure 5}

Evaluation of progression free survival (ECOG, Age, EN) with Prognostic factors in CD5 + patients

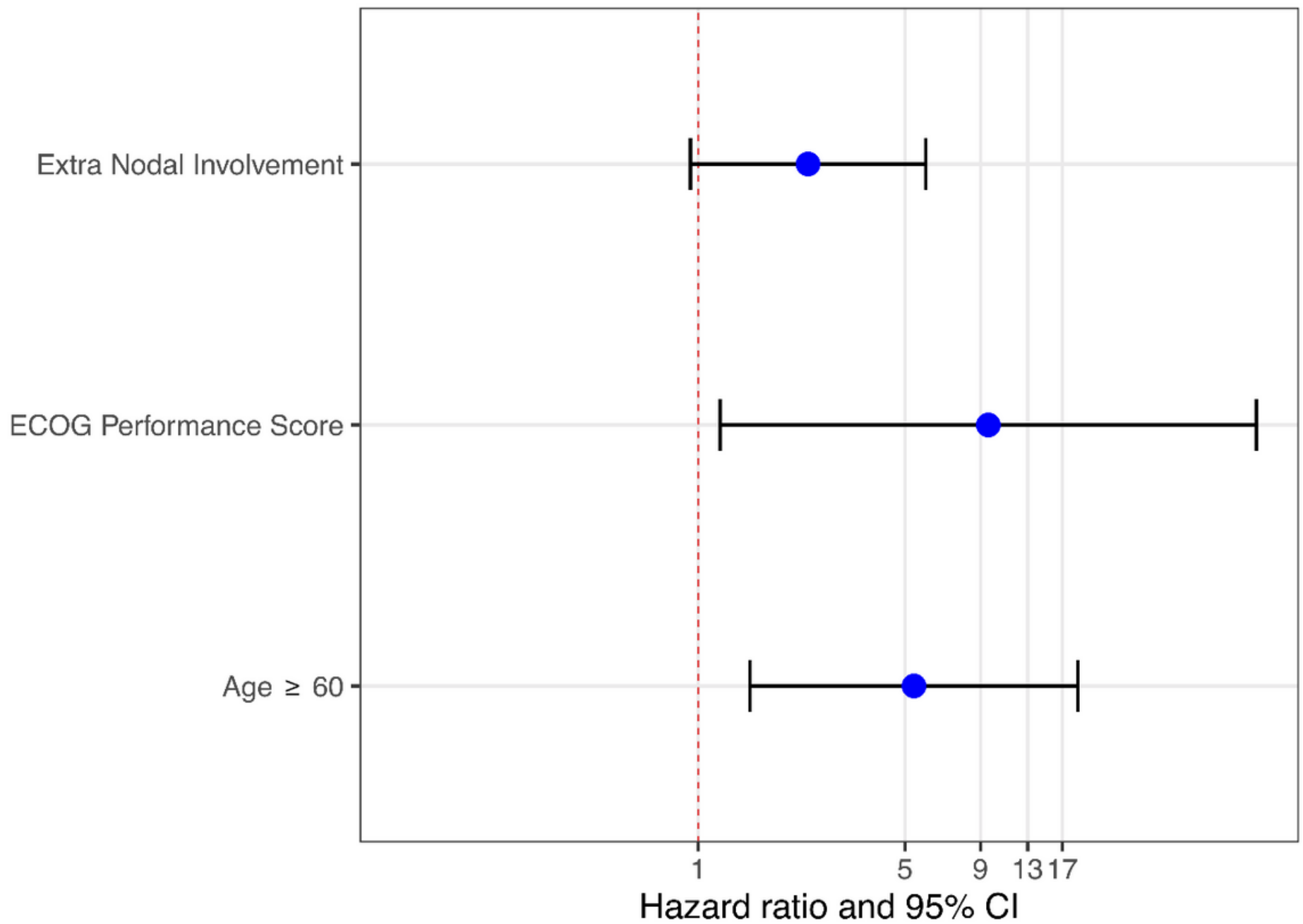

Figure 6

Multivariate analysis and overall survival ( $\mathrm{Y}$-axis is given in logarithmic scale) 


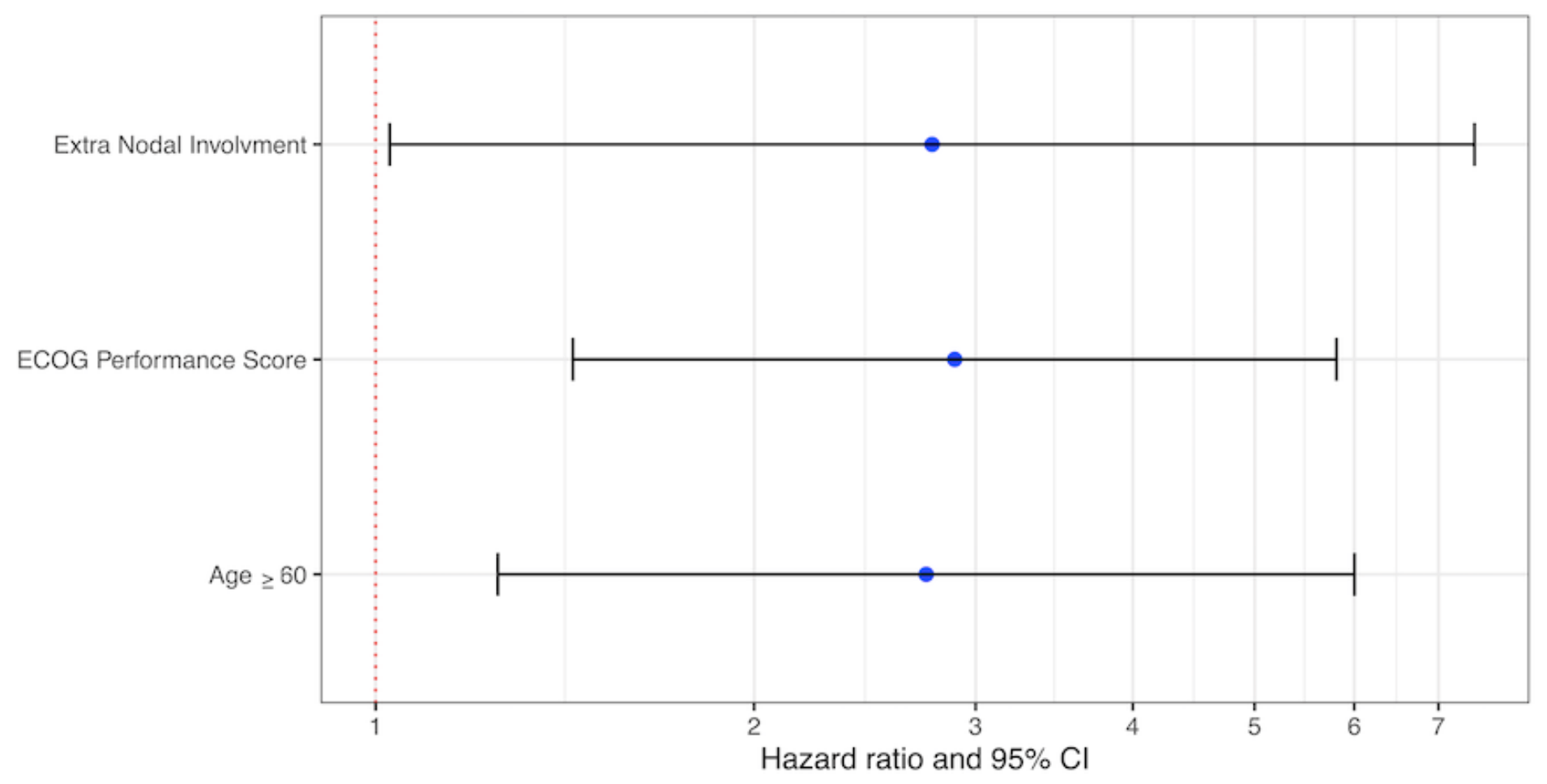

\section{Figure 7}

Multivariate analysis and Progression free survival ( $\mathrm{Y}$-axis is given in logarithmic scale) 